\title{
MICROBIOMA INTESTINAL: SEU POTENCIAL COMO UM NOVO ALVO TERAPÊUTICO
}

GUT MICROBIOME: ITS POTENTIAL AS A NEW THERAPEUTIC TARGET

\author{
ROQUE, Aline Tengan ${ }^{1}$; MAGALHÃES, Maurília de Cássiaํㅜ TAKETANI, Natalia Franco²; \\ ${ }^{1}$ Graduandas do Curso de Farmácia - Universidade São Francisco; \\ ${ }^{2}$ Professora do Curso de Farmácia - Universidade São Francisco; \\ mauriliacmagalhaes@hotmail.com
}

RESUMO. A evolução no campo da genômica e áreas afins nos últimos anos vêm permitindo estudos cada vez mais detalhados do microbioma humano. O trato gastrointestinal, mais precisamente o intestino, é o local que apresenta uma maior quantidade e diversidade de microrganismos, sofrendo então grande influência para a manutenção da homeostase, deste modo, nessa revisão procuramos resumir literaturas recentes sobre o microbioma intestinal e evidência de como sua composição no hospedeiro pode influenciar o seu metabolismo e a ocorrência de algumas doenças crônicas não transmissíveis, com elevada prevalência na população atual. O microbioma intestinal pode ser um importante intermediário entre a saúde e bem estar do hospedeiro quando em equilíbrio, podendo vir a atuar como um coadjuvante no tratamento e prevenção de determinadas patologias, é notável que a prevalência de bactérias patogênicas gastrointestinais, causará um desgaste nas interações consideradas benéficas, levando o indivíduo ao estado patológico.

Palavras-chave: microbioma intestinal; eixo cérebro-intestino; prebióticos; probióticos; disbiose;

\begin{abstract}
The evolution in the field of genomics and related areas in recent years have allowed more and more detailed studies of human microbiome. The gastrointestinal tract, more precisely the gut, is the site which presents a greater quantity and diversity of microorganisms, suffering then great influence on homeostasis maintenance, thus, in this review we have pursued to summarize recent literatures about gut microbiota and evidences on how its composition in the host may influence its metabolism and the occurrence of some non-transmissible chronic diseases with high prevalence in current populations. The intestinal microbiome can be an important intermediary between the health and well-being of the host when in balance, and may act as a coadjutant in the treatment and prevention of certain pathologies, it is notable that the prevalence of gastrointestinal pathogenic bacteria will cause a wear and tear on the interactions considered beneficial, leading the individual to the pathological state.
\end{abstract}

Keywords: Gut microbiome; Brain-bowel axis; Prebiotics; Probiotics; dysbiosis;

\section{INTRODUÇÃO}

O microbioma intestinal é composto por diversos microrganismos que colonizam o lúmen do trato gastrointestinal dos mamíferos, a caracterização desta comunidade varia para cada hospedeiro, além de estar suscetível a alterações endógenas e exógenas no decorrer do desenvolvimento do indivíduo (SEKIROV; RUSSELL; ANTUNES, 2010). 
A relação do microbioma intestinal e o organismo humano é simbiótica, onde as bactérias ocupam um ambiente rico em nutrientes e auxiliam no metabolismo intrínseco do hospedeiro (HOOPER, 2001). Tendo diversas funções como: a digestão de alimentos e a distribuição de gordura corporal (BÄCKHED et al., 2004), interferem também no sistema nervoso central por uma via de comunicação bidirecional, compreendendo o sistema nervoso entérico, o nervo vago, o sistema nervoso simpático e parassimpático e o sistema endócrino e imune (RHEE; POTHOULAKIS; MAYER, 2009).

O denominado eixo cérebro-intestino promove estreita ligação entre o sistema nervoso central (SNC) e entérico (SNE), de acordo com trabalhos experimentais realizados principalmente em animais, os quais tratam sobre as funções do microbioma intestinal, esses sistemas sugerem a capacidade dos microrganismos atuarem em distúrbios psicológicos ligados a deficiência funcional do intestino, tendo como exemplo a Síndrome do Intestino Irritável (SII) (SAULNIER et al., 2013).

A nível gastrointestinal o microbioma interage beneficamente com seu hospedeiro, mantendo funções como, controle da motilidade, absorção de nutrientes e integridade da barreira epitelial, quando quebrada esta interação, ocorre maior susceptibilidade a doenças e alterações no comportamento, como por exemplo, o estresse, que altera a composição normal do microbioma (COLLINS; BERCIK, 2009).

Sendo tamanha a influência das bactérias intestinais sobre a saúde, estudos vêm sendo cada vez mais voltados à elucidação do seu impacto no SNC e no comportamento do hospedeiro (RHEE; POTHOULAKIS; MAYER, 2009). Pesquisas relacionadas ao microbioma humano demonstram como modificações na população do microbioma intestinal exercem influência sobre a homeostase e podem colaborar no surgimento de doenças que permeiam desde a inflamação à obesidade. Experimentos realizados em animais, sendo os mesmo divididos em dois grupos, animais axênicos (sem germes) e animais expostos a infecções bacterianas patogênicas, bactérias probióticas ou antibióticos, indicam a microbiota intestinal como agente regulador na ansiedade, humor, cognição e dor, deste modo, este papel modulador pode vir a favorecer o desenvolvimento de novos campos terapêuticos para distúrbios do SNC (CRYAN; DINAN, 2012).

Estando o intestino e o cérebro intimamente atrelados, tal comunicação exerce um importante papel nas funções do sistema gastrointestinal bem como em estados psicológicos. Trabalhos recentes trazem a compreensão sobre a capacidade do cérebro em modular o SNE e deste modo, suas funções. Distúrbios no eixo intestino-cérebro estão relacionados à uma variedade de disfunções, como por exemplo, inflamação intestinal, obesidade, síndromes crônicas de dor abdominal e transtornos alimentares (MAYER, 2011).

A obesidade é uma epidemia mundial que envolve fatores genéticos e ambientais. Estudos recentes realizados em camundongos adultos axênicos, revelaram que o microbioma intestinal afeta a extração de energia a partir dos alimentos da dieta, contribuindo para o ganho de peso e armazenamento de gordura (BÄCKHED et al., 2004). Além disso, esta característica pode ser alterada através de transplante do microbioma intestinal, onde a colonização de camundongos sem germes com um microbioma oriundo de um indivíduo obeso resultou em um aumento significativamente maior na gordura corporal total do que a colonização com um microbioma oriundo de um indivíduo magro. Estes resultados identificam o microbioma intestinal como um fator adicional contribuinte para a fisiopatologia da obesidade (TURNBAUGH et al., 2006)

A relação do microbioma intestinal com o autismo é sugerida, uma vez que crianças portadoras deste distúrbio, frequentemente apresentam sintomas que incluem problemas 
gastrointestinais (DE THEIJE et al., 2011). O autismo é um distúrbio do desenvolvimento neurológico que possui como características comportamentos limitados, repetitivos e estereotipados que comprometem a comunicação e interação social do indivíduo. A forte relação dos sintomas gastrointestinais, tais como, constipação, dor abdominal, doença inflamatória intestinal, intolerância alimentar, diarreia e flatulência, levaram a estudos que indicam que as crianças com os sintomas do autismo mais agravantes tendem a ter sintomas gastrintestinais também mais graves e vice-versa, correlacionando possivelmente a progressão da neuropatologia parcialmente à composição anormal do microbioma intestinal. Vários estudos demonstraram alteração da comunidade microbiana intestinal quando comparado as crianças com autismo e as neurotípicas (ADAMS et al., 2011).

Outros estudos realizados sugerem que determinados metabólitos microbianos podem ser neuroativos, dessa forma conseguiriam alterar funções no cérebro resultando em alguns comportamentos do autismo (THOMAS et al., 2012)

Estudos recentes mostram que o microbioma intestinal pode interferir quimicamente no SNC por meio de mecanismos neurais, imunes e endócrinos. Resultados demonstram que o microbioma intestinal de um indivíduo portador de doença neurodegenerativa, possui notáveis alterações, entretanto ainda não está estabelecida uma relação de causa e efeito, a ligação de tais pontos poderia gerar um novo campo de estudos para determinar estratégias de prevenção e diagnóstico por meio do equilíbrio e saúde do microbioma intestinal (PARASHAR; UDAYABANU, 2017).

Nessa revisão procuramos explorar a influência do microbioma intestinal na ocorrência de algumas doenças crônicas não transmissíveis, com elevada prevalência na população atual.

\section{METODOLOGIA}

As informações contidas neste trabalho foram buscadas em Plataformas Científicas, como Google Acadêmico, Pubmed, Medline, Science Direct e Scielo. Foram utilizadas palavras chave como: microbioma intestinal; eixo cérebro-intestino; prebióticos; probióticos; disbiose. Foram utilizados artigos nacionais e internacionais nas línguas portuguesa e inglesa. No processo de busca foram consultados um total de 125 trabalhos científicos publicados entre os anos de 1995 a 2018, sendo 82 destes considerados relevantes para este trabalho.

\section{RESULTADOS E DISCUSSÃO}

Convivemos e somos colonizados por microrganismos desde o nosso nascimento, formando uma sinergia evolutiva essencial para a homeostasia do organismo hospedeiro. (BELKAID; NAIK, 2013). Estudos apontam que, em nível de composição, a comunidade bacteriana passa a se formar durante o início da vida, e é provável que diversos aspectos estejam relacionados com sua adaptação, como por exemplo, o tipo de parto (transmissão vertical materna), fatores genéticos do hospedeiro, dieta (bactérias denominadas transitórias são adquiridas pela alimentação), uso de antibióticos orais e de outros medicamentos, processos infecciosos no trato gastrointestinal e estresse.

O microbioma intestinal pode ser visto como um órgão adicional que tem funções cruciais em respostas imunes e processos fisiológicos ao decorrer do crescimento e vida do hospedeiro, além disso, o microbioma pode ser importante na modulação de fatores intestinais 
como a motilidade, homeostase da barreira intestinal e absorção de nutrientes (BERCIK; COLLINS; VERDU, 2012).

Trabalhos recentes mostram evidências que relacionam o microbioma e sua influência na resposta imune local e sistêmica, sendo esta distinta em cada parte do corpo. (MEDINI et al., 2008; COSTELLO et al., 2009). Análises comparativas incluindo vias aéreas, pele, cabelo, trato gastrointestinal, foram revelados táxons bacterianos predominantes em cada habitat, esses padrões estão sendo revelados através de avanços recentes de sequenciamento metagenômico que revela vias essenciais de sobrevivência dos microrganismos (HUTTENHOWER et al., 2012).

Nesta revisão bibliográfica traremos dados recentes sobre a interação do microbioma do trato gastrointestinal, que é o lar mais abundante de comensais e a sua relação com a saúde do hospedeiro, uma vez que esta demonstra extrema importância no desenvolvimento de patologias, já que a relação de simbiose hospedeiro-microrganismos é sensível à perturbações e a geração de uma disbiose pode torna-los "pathobiontes" auxiliando ou desencadeando reações propícias para o desenvolvimento de doenças (RUFF; KRIEGEL, 2015).

A camada mucosa gastrointestinal é uma barreira entre o epitélio intestinal e os microrganismos que ali residem, porém algumas espécies de bactérias filamentosas segmentadas (SFB) são capazes de penetrar nessa mucosa e em contato direto com o epitélio podem influenciar as funções imunológicas (BELKAID; NAIK, 2013). O número exacerbado de microrganismos e a sua grande diversidade, além da grande área intestinal ( 200 m2), é um frequente desafio para o sistema imune deste órgão, uma vez que este tem um importante papel na preservação da homeostase do hospedeiro (HOOPER; MACPHERSON, 2010).

$\mathrm{O}$ eixo cérebro-intestino, trata-se de uma comunicação bidirecional, supõe-se que a mesma é sustentada por vias neurais (sistema nervoso autônomo, sistema nervoso entérico, nervo vago) e humorais (citocinas, hormônios e neuropeptídios), sendo o microbioma intestinal um potencial sinalizador neste sistema através de seus metabólitos, como é evidenciado em estudos realizados com animais (BERCIK; COLLINS; VERDU, 2012).

O nervo vago $(\mathrm{NV})$, que parece ser o principal intermediário nesta comunicação, tem capacidade de detectar metabólitos provenientes da microbiota intestinal e diferir a informação até o sistema nervoso central (SNC), por meio de suas vias aferentes, dando origem a uma adaptação ou resposta (BONAZ; BAZIN; PELLISSIER, 2018). Cada indivíduo possui uma comunidade bacteriana intestinal com características únicas, entretanto é sugerido que o equilíbrio entre essas bactérias, colabore com a saúde do hospedeiro, acredita-se que ao ser diminuído o número de bactérias desejáveis, consequentemente seriam desencadeados processos patológicos causados por quebra nas interações gastrointestinais, endócrinas e imunes, interligadas por meio da simbiose. Essas informações lançam a suposição de que o microbioma entérico está relacionado com distúrbios do SNC e gastrointestinais e suas comorbidades, o que é reforçado pelo fato de que psicopatologias geralmente estão acompanhadas de problemas gastrointestinais como a síndrome do intestino irritável (SII) e doença inflamatória intestinal (DII) (CRYAN; O’MAHONY, 2011).

\section{Obesidade}

A obesidade pode ser definida como um desequilíbrio energético que é causado pela diferença negativa entre a ingesta calórica e gasto energético. De acordo com a Organização Mundial de Saúde (OMS), a obesidade e o sobrepeso têm sido cada vez mais incidentes, o que é preocupante, uma vez que estes indivíduos tornam-se predispostos ao desenvolvimento de 
comorbidades como a diabetes mellitus 2 (DM 2), doenças cardiovasculares e hepáticas. No entanto, os mecanismos causadores da obesidade permanecem parcialmente incompreendidos (PHILIPPE, 2017).

O microbioma intestinal é um importante intermediário entre o estilo de vida do hospedeiro e sua fisiologia, deste modo, alterações podem vir a causar distúrbios patológicos. Experimentos realizados em camundongos e também em humanos vêm demonstrando que o microbioma está associado com o teor de gordura corporal, e consequentemente pode estar envolvido com a obesidade.

O uso de animais axênicos, ou seja, criados sem a presença de microrganismos, em experimentos como o transplante de microbioma, avaliam a ligação entre o microbioma intestinal e doenças metabólicas, como a obesidade, e apontam sua influência sobre os processos metabólicos do hospedeiro (PHILIPPE, 2017). Nossa parcela de atuação nos processos metabólicos efetivos para a manutenção da homeostase é significativamente pequena se comparada com aquela proveniente do microbioma, sendo a aquisição de nutrientes e processamento de xenobióticos, processos metabólicos benéficos fornecidos ao hospedeiro por meio da simbiose (SEKIROV; RUSSELL; ANTUNES, 2010).

Estudos realizados com camundongos que abrigam um microbioma desde seu nascimento mostram que ao serem comparados aos camundongos axênicos, os primeiros possuem $42 \%$ a mais de gordura corporal total, ainda que seu consumo diário de carboidratos (57\%) e gordura (5\%) foi de $29 \%$ menor do que seus homólogos (B ÄCKHED et al., 2004). O fato de que os camundongos axênicos necessitam de uma dieta mais calórica para manter seu peso corporal sugere a possibilidade de que existem mecanismos pelos quais o microbioma pode aumentar a disponibilidade calórica dos nutrientes consumidos (SEKIROV; RUSSELL; ANTUNES, 2010).

A introdução de microrganismos provenientes do ceco de camundongos convencionais em axênicos traz como resultado acréscimo de $60 \%$ na sua gordura corporal mesmo que submetidos a dieta reduzida, além disso, os níveis de leptina, glicose e insulina são elevados, o que também contribui com o aumento da gordura corporal (BÄCKHED et al., 2007). O transplante de microrganismos intestinais de camundongos com perfil obeso em receptor axênico também eleva o volume de gordura corporal aproximadamente 3 (três) vezes mais do que àqueles que receberam o material de doadores com perfil magro (TURNBAUGH et al., 2006), do mesmo modo que o transplante do microbioma intestinal de um humano com características obesas, para camundongos normais e isentos de germes, trouxe como resultado o rápido ganho de gordura corporal por parte dos receptores além de uma rápida mudança na composição microbiana colonizada no receptor, enquanto que àqueles que foram transplantados com microbioma de um individuo magro, não tiveram alterações em seu peso (RIDAURA et al., 2013).

É observado que camundongos axênicos são menos suscetíveis a desenvolver a obesidade do que os convencionais, ainda que tenham uma ingesta rica em gordura e açúcar. Não se sabe ao certo o mecanismo pelo qual esses camundongos são menos propensos à obesidade, entretanto é observada certa melhoria quanto aos fatores de sensibilidade à insulina e tolerância à glicose, mesmo se submetidos a regime dietético rico em gordura, além disso, esses camundongos, onde a microbiota é ausente, apresentam alterações no metabolismo do colesterol. Deste modo, é provável que o metabolismo do colesterol e a sensibilidade insulínica, sejam fatores metabólicos que sofrem influência do microbioma intestinal, o que sugere sua participação no desenvolvimento da obesidade (PHILIPPE, 2017). 
Os microrganismos intestinais tem a capacidade de promover a digestão de polissacarídeos indigestíveis, provenientes da dieta, em metabólitos denominados ácidos graxos de cadeia curta (BELL, 2015), sendo o acetato, propionato e butirato os principais, e os quais fornecem aproximadamente $10 \%$ de energia diária ao organismo hospedeiro, indivíduos com obesidade apresentam maior concentração fecal destes ácidos graxos. (FERNANDES et al., 2014). Esses metabólitos tem como função a regulação de processos fisiológicos do hospedeiro, como moléculas sinalizadoras, podendo influenciar inclusive o metabolismo de lipídeos, glicose e colesterol em diversos tecidos, sendo outro aspecto importante, sua capacidade de controlar a excreção de hormônios relacionados à saciedade e controle da motilidade (SANDHU et al., 2016), mecanismo este associado à sua capacidade de se acoplar à proteínas específicas do epitélio intestinal favorecendo a excreção do hormônio peptídico PYY, o qual pode atuar diminuindo a velocidade do trânsito intestinal e aumentando assim a absorção de nutrientes (SAMUEL et al., 2008).

Outro mecanismo explorado seria a capacidade de supressão provocada pelo microbioma sobre a ação do fator adipocitário FIAF (Fasting Induced Adipose Factor), o qual é produzido pelo intestino, fígado e tecido adiposo. Sua principal função consiste na inibição da lipase lipoproteica, deste modo, ao ser inibido o FIAF favorece a ação dessa enzima causando maior absorção de ácidos graxos associada a maior armazenamento de triglicérides no tecido adiposo. (B ̈̈CKHED et al., 2004).

Para mais, a dieta do hospedeiro, também é um fator importante que influencia diretamente a composição do microbioma, evidenciando que hábitos alimentares pouco saudáveis podem contribuir com essas alterações (SANZ et al., 2014). Experimentos realizados com camundongos geneticamente obesos trazem como resultado maior número de Firmicutes em relação ao número de Bacteroidetes, quando comparados a camundongos selvagens. Ao estudar seres humanos com perfil obeso, observa-se que estes quando submetidos à dieta para perda de peso, apresentam menor número de Firmicutes e maior número de Bacteroidetes, além de reconstituição da microbiota semelhante àqueles indivíduos de perfil magro (LEY et al., 2005).

Em resumo, pressupõe-se que o microbioma intestinal pode vir a favorecer o desenvolvimento da obesidade por meio de uma série de mecanismos que, embora não estejam completamente elucidados, estão correlacionados o perfil dietético do hospedeiro, funções metabólicas dos microrganismos intestinais e/ou a disbiose (SANDHU et al., 2016).

\section{Estresse e Depressão}

Atualmente é crescente o interesse sobre a perspectiva de que o microbioma seja um potencial agente ligado á química cerebral e consequentemente comportamento do hospedeiro através de uma comunicação bidirecional entre o cérebro e o intestino, onde estão incluídos os sistemas neuroendócrino, imunológico, nervoso autônomo e entérico (FOSTER; NEUFELD, 2013). Diversas estratégias vêm sendo usadas para fornecer resultados evidentes, modelos animais com quadro de psicopatologia são peças chave nesta complexa investigação (CRYAN, 2013).

Estudos demonstram que o eixo intestino-cerebral, através do microbioma desempenha funções importantes no desenvolvimento e comportamento cerebral, sendo o sistema imunológico um dos intermediários nesta interação. A comunidade microbiana é capaz de desempenhar a modulação da maturação e funcionalidade de células imunitárias do 
tecido nervoso central, além de participar da ativação das células imunitárias presentes em outros tecidos periféricos. (FUNG; OLSON; HSIAO, 2017).

Ao interagir com o sistema imune do hospedeiro, o microbioma pode influenciar seu neurodesenvolvimento além de interferir em processos psicológicos e induzir doenças depressivas. Estudos que fizeram o uso de camundongos axênicos com distúrbios imunes, demonstram que a colonização com bactérias comensais, pode restaurar a imunidade do animal. Além disso, a suplementação com probióticos resulta em diminuição de marcadores inflamatórios no intestino de animais com colite, além de diminuir os níveis de corticosterona em animais induzidos ao estresse, suavizando sintomas de ansiedade e depressão (HAYLEY; AUDET; ANISMAN, 2016).

A depressão é uma desordem do humor onde geralmente o paciente perde o prazer e interesse nas atividades do dia a dia, sua etiologia ainda não está completamente elucidada, entretanto é sugerido que fatores com a ativação do sistema imune, interações entre o sistema nervoso central e o microbioma, inflamação, sistema hipotálamo-hipófise-adrenal (HHA), possam estar relacionados com sua origem. Inúmeras evidências indicam que a composição do microbioma também pode estar relacionada com a suscetibilidade do hospedeiro a desenvolvê-la (CRYAN; DINAN, 2012). A principal característica do individuo depressivo é a perda da sensação de bem-estar e tristeza crônica, sendo a serotonina o neurotransmissor responsável pela regulação do humor, acredita-se que a falha em sua receptação seja um importante precedente à depressão.

O sistema serotoninérgico tem como função o controle das áreas cerebrais relacionadas ao sentimento e comportamento (BELMAKER; AGAM, 2008). Além de atuar no SNC, a serotonina também possui funções motoras e sensoriais no sistema nervoso entérico, onde regula diversas funções como a motilidade e as secreções intestinais. $\mathrm{O}$ triptofano, seu principal precursor, é um aminoácido essencial obtido pela dieta, sua absorção no intestino o leva á corrente sanguínea onde atravessa a barreira hemato-encefálica e participa da produção da serotonina. Entretanto o intestino é responsável pela maior parte de produção e armazenamento de serotonina, por meio de células enterocromafins ativadas por determinadas bactérias (O'MAHONY et al., 2014), o que evidencia que a microbiota pode ter um importante papel em sua modulação. Complementando estes fatos, estudos mostram que camundongos axênicos apresentam níveis de serotonina sérica e colônica diminuídos em comparação aos convencionais (FUNG; OLSON; HSIAO, 2017).

Evidências indicam que a comunidade bacteriana, ao sofrer disbiose, ou seja, uma disfunção entre as espécies bacterianas benéficas e nocivas presentes no meio, pode afetar o sistema imunológico desencadeando o processo inflamatório intestinal (MATSUOKA; KANAI, 2015). Pacientes com depressão apresentam propriedades cardinais do processo inflamatório em associação a sintomas como fadiga, insônia e distúrbios cognitivos (MILLER; MALETIC; RAISON, 2008). Esta relação possivelmente se dá através de mecanismos que envolvem alterações na composição microbiana prejudicando seu equilíbrio e desencadeando liberação de citocinas e fatores inflamatórios com consequências sistêmicas influenciando diversas vias contribuindo com a depleção de serotonina e doença depressiva. (HAYLEY; AUDET; ANISMAN, 2016). Quando essas citocinas atingem o SNC são capazes de modular fatores como a liberação, receptação e síntese de neurotransmissores importantes para o humor e bem-estar, como por exemplo, a serotonina. (MILLER; MALETIC; RAISON, 2008).

Através de diversos mecanismos, essas citocinas são capazes de ativar as enzimas indoleamina-2,3-dioxigenase (IDO) presente nas micróglias e a triptofano-2,3-dioxigenase 
(TDO) presente no fígado, a ativação destas enzimas ocasionará em maior síntese de quinurenina a partir da quebra do triptofano, sendo esta posteriormente metabolizada e convertida em ácido quinurênico e ácido quinolínico neurotóxico. Deste modo a diminuição do triptofano disponível levará a diminuição da síntese de serotonina podendo desencadear o estado depressivo bem como, o aparecimento de sintomas gastrointestinais regulados por esse neurotransmissor. Além disso, o ácido quinolínico neurotóxico, trata-se de uma substância potencialmente causadora de neurodegeneração e comprometimento cognitivo alto (O’MAHONY et al., 2014).

Por outro lado, as citocinas pró-inflamatórias (interleucina-1, interleucina-6 e fator de necrose tumoral alfa), podem exercer funções moduladoras sobre hormônios específicos que podem causar hiperatividade no eixo hipotálamo hipófise adrenal (HHA), alterações nesse sistema são evidenciadas em diferentes casos de psicopatologias, como a depressão (BRIEN; SCOTT; DINAN, 2004). O eixo HHA trata-se de uma via que liga o hipotálamo à glândula hipófise e as glândulas supra-renais, responsável por gerar resposta ao estresse, o qual pode ser definido como uma perturbação da homeostase do organismo, que pode ser provocada por fatores físicos, psicológicos ou imunes, vindo a provocar alterações prejudiciais, sendo desencadeada uma resposta a fim de devolver o equilíbrio uma vez que, tenha cessado o estímulo. Sua funcionalidade é modulada pela excreção do fator de liberação hormonal adrenocorticotrófico e de vasopressina do hipotálamo ativando a secreção do hormônio adrenocorticotrofina da hipófise, estimulando a secreção de glicocorticoides, como o cortisol (humanos) e corticosterona (roedores) do cortéx adrenal, os quais interagem com seus receptores alvos regulando funções periféricas e centrais, como controle do estresse, além de imunidade e metabolismo (REA; DINAN; CRYAN, 2016).

No nascimento o HHA ainda se encontra imaturo passando a se desenvolver somente durante o crescimento, o que também acontece com a comunidade microbiana intestinal, sugerindo que sua programação está conectada ao microbioma. Estudos utilizando o método de separação materna em camundongos demonstram que o estresse provocado no filhote pode ter como consequência alterações na composição e variedade do microbioma em longo prazo, vindo a causar distúrbios na reatividade do eixo. (FOSTER; NEUFELD, 2013).

Embora os mecanismos não estejam completamente elucidados, pesquisas relacionadas à neuroendocrinologia, tem citado a hiperatividade do eixo HHA como um fator importante no desenvolvimento de patologias relacionadas ao humor, como a depressão, e do desempenho cognitivo, visto que, pacientes depressivos apresentam elevação nos níveis de cortisol e falhas cognitivas, quando comparados a controles saudáveis. (KELLER et al., 2016).

O papel do microbioma na regulação das alterações associadas ao estresse e comportamento se reforça a partir de estudos realizados com camundongos axênicos, esses animais quando expostos ao estresse apresentam hiperatividade do eixo HHA, a melhora do quadro é vista, uma vez que, o intestino é colonizado. Deste modo, é evidente que desequilíbrios na comunidade microbiana podem causar processos inflamatórios e neuroendócrinos, que terão como consequência uma potencial manifestação de comportamentos ansiosos e depressivos gerados no hospedeiro (FOSTER; RINAMAN; CRYAN, 2017).

\section{Autismo}

O transtorno do espectro do autismo (TEA) é caracterizado por déficit persistente na comunicação social, dificuldade de concentração, problemas comportamentais e repetitivos, 
muitas vezes acompanhados de disfunção gastrointestinal, dores abdominais crônicas e intolerâncias alimentares (CARABOTTI et al., 2015), as quais estudos recentes revelam ter uma forte ligação com os sistemas intestinais-imunes-cerebrais, através da comunicação bidirecional do eixo intestino-cérebro onde a principal via de comunicação é o nervo vago. $\mathrm{O}$ SNC influencia as funções gastrointestinais como motilidade, secreção e produção de mucina e o intestino via liberação de hormônios intestinais como a 5-hidroxitriptamina (5-HT) de células intestinais, e produtos bacterianos influenciando o comportamento do hospedeiro (COLLINS; SURETTE; BERCIK, 2012).

No transtorno do espectro autista $30 \%$ das crianças apresentam o nível elevado de serotonina no sangue total (MULLER; ANACKER; VEENSTRA-VANDERWEELE, 2016). A 5-TH é encontrada abundantemente no trato gastrointestinal cerca de $90 \%$ e no sistema nervoso central (SNC), sendo essa de grande importância para diferenciação e migração neuronal, além do crescimento axonal, mielinização e sinapses (HOMBERG; KOLK; SCHUBERT, 2013).

Em um estudo realizado em uma clínica especializada em TEA por Molloy e Manning-Courtney (2003) com 137 crianças, com idade entre 2 e 8 anos pode ser observado que $24 \%$ apresentavam pelo menos um sintoma gastrointestinal crônico, sendo a diarreia um total de $17 \%$ dessas ocorrências (MOLLOY, 2003). Pesquisas nos mostram também evidências sobre a permeabilidade intestinal, onde pacientes com autismo apresentaram valores anormais sendo $36.7 \%$ quando comparados com seus parentes $21.2 \%$ e com indivíduos normais $4.8 \%$, nesse mesmo estudo $45.5 \%$ das crianças com autismo apresentavam constipação, $34.1 \%$ diarreia e outras sintomatologias gastrointestinais somavam $15.9 \%$ (DE MAGISTRIS et al., 2010).

A disbiose intestinal enfraquece o sistema imunológico da mucosa local, prejudicando a permeabilidade e dessa forma aumentando a absorção de substâncias tóxicas na circulação sistêmica (XU et al., 2015). O uso excessivo de antibióticos orais é associado ao autismo uma vez que a alteração no microbioma intestinal por meio destes agentes pode vir a permitir que outros microrganismos considerados desencadeantes do autismo se colonizem, vindo a desenvolver a doença (SEKIROV; RUSSELL; ANTUNES, 2010).

\section{Microbioma intestinal como alvo terapêutico}

\section{Probióticos}

Os probióticos são definidos como "microrganismos vivos que, quando administrados em quantidades adequadas, conferem um benefício à saúde do hospedeiro" (HILL et al., 2014). O avanço das pesquisas que exploram essa rede de comunicação entre o microbioma gastrointestinal e o cérebro, através de comunicações moleculares, sendo estas, neuronal direta através do nervo vago, mediadores de sinalização endócrinos e imunológicos que podem sofre com a disbiose de microrganismos propagando sinais nocivos propiciando uma inflamação de baixo grau, levando ao aumento do estresse oxidativo, homeostase da energia desequilibrada e um aumento geral na degeneração celular (NOBLE; HSU; KANOSKI, 2017)

Alguns microrganismos, como mostrado nos achados relatados nesta revisão produzem metabólitos que cruzam vias bioquímicas interagindo no desenvolvimento de doenças, os probióticos se estabelecem como comensais e criam um ambiente intestinal saudável, equilibrando populações bacterianas e promovendo sua ação metabólica favorável apoiando a compreensão dos benefícios dos probióticos como alternativa terapêutica 
(WESTFALL et al., 2017). Modelos murinos induzidos ao estresse crônico e tratados previamente com probiótico tiveram os níveis plasmáticos de corticosterona, adrenalina e noradrenalina diminuídos (AIT-BELGNAOUI et al., 2014). Assim como os achados em outro estudo realizado por Bravo e seus colaboradores (2011) que demonstraram relevância no uso de probióticos para transtornos relacionados à ansiedade e depressão em camundongos (BRAVO et al., 2011).

Eles possuem diversos mecanismos de ação como, capacidade de modular e afetar outros microrganismos através de competição por nutrientes e adesão ao epitélio, produção de compostos com ação inibitórias de bactérias gram-positivas e gram-negativas, dentre elas estão os ácidos orgânicos, peróxido de hidrogênio e bacteriocinas, alteração do pH local, além de possuírem ação imunoestimuladora (SERVIN, 2004; CLEUSIX et al., 2008; SENGPUTA. R. et al., 2013). Sua eficácia probiótica irá depender das moléculas apresentadas em sua superfície, suas propriedades metabólicas e os componentes que secretam (BIENENSTOCK; KUNZE; FORSYTHE, 2016).

Os probióticos mostraram promover a integridade da barreira intestinal através de estudos de colite em camundongos através da capacidade de adesão à superfície das mucosas e de inibição da ligação de outras bactérias patogênicas (MADSEN et al., 2001; UKENA et al., 2007). Em um estudo ratos submetidos a estresse psicológico crônico tiveram translocação bacteriana, mas os controles que foram pré-tratados com probióticos não tiveram essa translocação evidenciando a ação probiótica na integridade da barreira epitelial (ZAREIE et al., 2006). Em outro estudo pode-se identificar ação ansiolítica transmitida para o cérebro através do nervo vago (BERCIK et al., 2011). Em ensaio clínico mostrou-se efeitos psicológicos benéficos, além da diminuição de cortisol, e atividade ansiolítica em murinos (MESSAOUDI et al., 2011).

Os efeitos benéficos dos probióticos na ansiedade e depressão podem ser explicados pela exclusão competitiva de patógenos intestinais deletérios (RAMIAH; REENEN; DICKS, 2008), diminuição de citocinas pró-inflamatórias e comunicação com o sistema nervoso central via fibras sensoriais vagais, levando a alterações nos níveis ou funções dos neurotransmissores (JOFFRE, 2009). Além da sua ação sobre as psicopatologias, como citado anteriormente, os probióticos possuem potencial efeito na prevenção e tratamento de obesidade, fator este que também está sendo bastante estudado. Especula-se que este efeito esteja associado ao equilíbrio energético produzido pelos microrganismos, diminuindo o ganho de peso e aumentando a homeostase da glicose-insulina e atenuando a hiperglicemia e a intolerância à glicose (WANG et al., 2015).

\section{Prebióticos}

Pesquisas estão explorando a possibilidade de modulação da comunicação do eixo intestino-cérebro alterando o microbioma residente através da dieta, uma vez que, mudanças dos componentes nutricionais alteram o microbioma gastrointestinal influenciando $o$ hospedeiro. Evidências relatadas pelo estudo em camundongos que receberam dieta acrescida de $50 \%$ de carne bovina magra mostraram uma maior diversidade bacteriana através de amostras coletadas de fezes e houve aumento tanto da memória de trabalho quanto de referência que são medidas pelo armazenamento temporário e em longo prazo de informação, além de exibirem níveis reduzidos de comportamento de ansiedade quando comparados aos camundongos controle que receberam dieta padrão para roedores (LI et al., 2009). 
Bactérias gram-negativas possuem em sua membrana lipopolissacarídios (LPS), que tem sido implicado em inflamações de baixo grau (endotoxemia) que está presente na obesidade, sendo a microbiota intestinal um ator crucial nessa patologia, sua modulação é bem vista sendo uma ferramenta interessante para o tratamento. Em roedores obesos que recebem uma dieta hiperlipídica observou-se o aumento de bactérias gram-negativas e de LPS no plasma o que caracterizou a endotoxemia (CANI et al., 2007), que pode ser causa por mecanismos deficientes da barreira intestinal o que proporciona com que essas substâncias caiam na corrente sanguínea assim como microrganismos patogênicos.

Em uma pesquisa realizada com murinos tratados com prebióticos (carboidratos fermentáveis produzidos a partir de Cereais) mostrou-se efetivo na melhora das funções de barreira intestinal e na endotoxemia metabólica na obesidade (CANI et al., 2007); (NEYRINCK et al., 2012). Assim como, oligossacarídeos não digeríveis, resistentes às ações de enzimas salivares e intestinais, mostraram inibir diretamente a aderência de patógenos à superfície da célula epitelial hospedeira em um estudo com células de linhagem intestinal e Escherichia coli enteropatogênica, onde houve a diminuição de 65 à $70 \%$ da bactéria nas células (SHOAF et al., 2006). Além disso, demonstraram propriedades antinflamatórias e capacidade de proteção contra o comportamento semelhante à ansiedade induzido por endotoxina (SAVIGNAC et al., 2016).

\section{Medicamentos}

Os medicamentos têm sido sugeridos como possíveis variáveis que podem atuar influenciando o microbioma intestinal (SCHMIDT; RAES; BORK, 2018), o qual pode influenciar a eficácia ou toxicidade de determinadas drogas através de mecanismos que ainda estão sendo estudados (VÁZQUEZ-BAEZA et al., 2017).

Os antibióticos de amplo espectro, usados com intuito de diminuir patógenos, estão associados a alterações na comunidade microbiana tanto a curto quanto em longo prazo (SCHMIDT; RAES; BORK, 2018), podendo influenciar e/ou reduzir a microbiota intestinal de diferentes formas, uma vez que existem diferentes classes, com propriedades exclusivas, além de fatores como dose e tempo de tratamento, ação e alvo terapêutico. (IIZUMI et al., 2017). O mais intrigante é o fato de que novos estudos mostram que drogas não-antibióticas também podem exercer certas influências sobre o microbioma intestinal (LE BASTARD et al., 2017).

Os antinflamatórios, mais especificamente aqueles pertencentes à classe dos nãoesteroidais (AINES), podem estar associados a prejuízos no intestino delgado, sendo a gravidade dependente da composição da microbiota no momento da administração deste medicamento. Estudos demonstram que a prevalência de bactérias gram-negativas corresponde a danos mais severos. Especula-se que haja uma possibilidade de que o uso de probióticos possa auxiliar na redução dos efeitos negativos provocados pelos AINES em humanos, entretanto mais estudos são necessários (VÁZQUEZ-BAEZA et al., 2017).

Estudos com pacientes portadores de Diabetes Mellitus 2 (DM2), demonstram que a terapia com a metformina tem efeito sobre a comunidade microbiana (TRIPATHI et al., 2018). A metformina é o principal medicamento administrado em pacientes com DM2, sua principal ação terapêutica consiste na inibição da síntese de glicose pelo fígado (WU et al., 2017). Supõe-se que a microbiota é capaz de regular os efeitos benéficos da metformina relacionados ao metabolismo da glicose. (FORSLUND et al., 2015). Especula-se que pacientes portadores de DM2 apresentem alterações quanto à diversidade e composição da 
microbiota, principalmente no que se refere produção de ácidos graxos de cadeia curta, como o butirato. A terapia com metformina pode ser capaz de aumentar as espécies bacterianas produtoras deste componente, o qual é benéfico para o hospedeiro uma vez que, após interação com receptor especifico, colabora com os mecanismos de redução da glicólise e aumento da captação da glicose. Deste modo, é possível que aja uma relação entra a metformina e o butirato, quanto à homeostase dos níveis glicêmicos. (MANIAR et al., 2017).

Ainda não é possível afirmar como ou por quais mecanismos os medicamentos podem afetar o microbioma, existem questões que discutem se essa interferência ocorre diretamente impedindo o crescimento bacteriano e/ou induzindo a ocorrência de morte celular, ou ainda indiretamente por meio de interações com o hospedeiro, além disso, não se sabe ao certo se medicamentos específicos tem mais ou menos tendência de provocar tais efeitos. Testes realizados in vitro com mais de mil medicamentos em contraposição à aproximadamente 40 cepas bacterianas intestinais humanas distintas, demonstraram que cerca de $20 \%$ dos medicamentos em análise, impediram o crescimento de pelo menos uma das cepas, e aproximadamente 40 drogas inibiram cerca de 10 cepas, evidenciando maior espectro. Abordagens mais aprofundadas sobre estes resultados fazem-se necessárias, ainda que grande parte das alterações do microbioma intestinal não afetem de modo marcante as terapias medicamentosas, o entendimento destes mecanismos é essencial para a evolução da prevenção e tratamento de doenças baseadas na manipulação da comunidade microbiana. (SPANOGIANNOPOULOS; TURNBAUGH, 2018).

\section{CONCLUSÃO}

O desenvolvimento de determinadas patologias está relacionado ao desarranjo entre os organismos que vivem no sistema tegumentar e tecido da mucosa do intestino humano, o qual convive em simbiose desenvolvendo-se logo após o nascimento, tendo em vista sua influência na fisiologia, na manutenção do equilíbrio de tecidos e órgãos, principalmente na obtenção de energia a partir da dieta e desenvolvimento do sistema imunológico.

Fatores extrínsecos e/ou intrínsecos podem ser responsáveis por desencadear tal desarmonia, trazendo como consequência alterações na flora intestinal levando ao aumento da suscetibilidade do individuo ao estado patológico. Tal descoberta é recente e de grande importância para a área da saúde, pois através do crescente avanço tecnológico associado à expansão do conhecimento sobre o microbioma, novas possibilidades de intervenção farmacológica podem ser geradas.

O reconhecimento mais aprofundado das diversas interações existentes entre os seres humanos e seus simbiontes, poderá nos mostrar um verdadeiro potencial do microbioma como alvo terapêutico, podendo ser manipulado por algum tratamento prévio e/ou acompanhamento, com finalidade de melhorar o resultado da terapêutica em pacientes, além de prevenção ao desenvolvimento de uma série de patologias. Todavia, muitos estudos ainda precisam ser realizados, pois a individualidade de cada organismo hospedeiro é um fator determinante para o sucesso do tratamento visto que, além da diversidade da comunidade microbiana, existem fatores genéticos, socioculturais e ambientais, o que reforça o fato de que cada organismo é único. Deste modo, perspectivas futuras poderão apontar o microbioma intestinal como um fator a ser considerado relevante no processo terapêutico, de acordo com todas as particularidades de cada indivíduo. 


\section{REFERÊNCIAS}

ADAMS, J. B. et al. Gastrointestinal flora and gastrointestinal status in children with autism - comparisons to typical children and correlation with autism severity. BMC Gastroenterology, v. 11, n. 1, p. 22, 2011.

AIT-BELGNAOUI, A. et al. Probiotic gut effect prevents the chronic psychological stress-induced brain activity abnormality in mice. Neurogastroenterology and Motility, v. 26, n. 4, p. 510-520, 2014.

BÄCKHED, F. et al. The gut microbiota as an environmental factor that regulates fat storage. Proceedings of the National Academy of Sciences of the United States of America, v. 101, n. 44, p. 15718-23, 2004.

$\mathrm{BÄCKHED,} \mathrm{F.} \mathrm{et} \mathrm{al.} \mathrm{Mechanisms} \mathrm{underlying} \mathrm{the} \mathrm{resistance} \mathrm{to} \mathrm{diet-induced} \mathrm{obesity} \mathrm{in}$ germ-free mice. Proceedings of the National Academy of Sciences, v. 104, n. 3, p. 979-984, 2007.

BELKAID, Y.; NAIK, S. Compartmentalized and systemic control of tissue immunity by commensals. Nature Immunology, v. 14, n. 7, p. 646-653, 2013.

BELL, D. S. H. Changes seen in gut bacteria content and distribution with obesity: Causation or association? Postgraduate Medicine, v. 127, n. 8, p. 863-868, 2015.

BELMAKER, R. H.; AGAM, G. Major Depressive Disorder. The new england journal of medicine, 2008.

BERCIK, P. et al. The anxiolytic effect of Bifidobacterium longum NCC3001 involves vagal pathways for gut-brain communication. Neurogastroenterology and Motility, v. 23, n. 12 , p. 1132-1139, 2011.

BERCIK, P.; COLLINS, S. M.; VERDU, E. F. Microbes and the gut-brain axis. Neurogastroenterology and Motility, v. 24, n. 5, p. 405-413, 2012.

BIENENSTOCK, J.; KUNZE, W.; FORSYTHE, P. The Microbiome-Gut-Brain Axis and the Consequences of Infection and Dysbiosis. The American Journal of Gastroenterology Supplements, v. 3, n. 2, p. 33-40, 2016.

BONAZ, B.; BAZIN, T.; PELLISSIER, S. The vagus nerve at the interface of the microbiota-gut-brain axis. Frontiers in Neuroscience, v. 12, n. FEB, p. 1-9, 2018.

BRAVO, J. A. et al. Ingestion of Lactobacillus strain regulates emotional behavior and central GABA receptor expression in a mouse via the vagus nerve. Proceedings of the National Academy of Sciences, v. 108, n. 38, p. 16050-16055, 2011.

BRIEN, S. M. O.; SCOTT, L. V; DINAN, T. G. Cytokines : abnormalities in major depression and implications for pharmacological treatment. Human 
Psychopharmacology, n. July, p. 397-403, 2004.

CANI, P. D. et al. Metabolic Endotoxemia Initiates Obesity and Insulin Resistance. Diabetes, v. 56, n. July, p. 1761-1772, 2007.

CARABOTTI, M. et al. The gut-brain axis: Interactions between enteric microbiota, central and enteric nervous systems. Annals of Gastroenterology, v. 28, n. 2, p. 203-209, 2015.

CLEUSIX, V. et al. Glycerol induces reuterin production and decreases Escherichia coli population in an in vitro model of colonic fermentation with immobilized human feces. FEMS Microbiology Ecology, v. 63, n. 1, p. 56-64, 2008.

COLLINS, S. M.; BERCIK, P. The Relationship Between Intestinal Microbiota and the Central Nervous System in Normal Gastrointestinal Function and Disease. Gastroenterology, v. 136, n. 6, p. 2003-2014, 2009.

COLLINS, S. M.; SURETTE, M.; BERCIK, P. The interplay between the intestinal microbiota and the brain. Nature Reviews Microbiology, v. 10, n. 11, p. 735-742, 2012.

COSTELLO, E. K. et al. Bacterial community variation in human body habitats across space and time. Science, v. 326, n. 5960, p. 1694-1697, 2009.

CRYAN, J. F.; DINAN, T. G. Mind-altering microorganisms: the impact of the gut microbiota on brain and behaviour. Nature Reviews Neuroscience, v. 13, n. 10, p. 701$712,2012$.

CRYAN, J. F.; O'MAHONY, S. M. The microbiome-gut-brain axis: From bowel to behavior. Neurogastroenterology and Motility, v. 23, n. 3, p. 187-192, 2011.

CRYAN, T. G. D. \& J. F. Melancholic microbes : a link between gut microbiota and depression? p. 713-719, 2013.

DE MAGISTRIS, L. et al. Alterations of the intestinal barrier in patients with autism spectrum disorders and in their first-degree relatives. Journal of Pediatric Gastroenterology and Nutrition, v. 51, n. 4, p. 418-424, 2010.

DE THEIJE, C. G. M. et al. Pathways underlying the gut-to-brain connection in autism spectrum disorders as future targets for disease management. European Journal of Pharmacology, v. 668, n. SUPPL. 1, p. 70-80, 2011.

FERNANDES, J. et al. Adiposity, gut microbiota and faecal short chain fatty acids are linked in adult humans. Nutrition and Diabetes, v. 4, n. JUNE, 2014.

FORSLUND, K. et al. Disentangling type 2 diabetes and metformin treatment signatures in the human gut microbiota. Nature, v. 528, n. 7581, p. 262-266, 2015.

FOSTER, J. A.; NEUFELD, K. M. Gut - brain axis : how the microbiome influences 
anxiety and depression. Trends in Neurosciences, v. 36, n. 5, p. 305-312, 2013.

FOSTER, J. A.; RINAMAN, L.; CRYAN, J. F. Stress \& the gut-brain axis : Regulation by the microbiome. Neurobiology of Stress, 2017.

FUNG, T. C.; OLSON, C. A.; HSIAO, E. Y. Interactions between the microbiota , immune and nervous systems in health and disease. Nature Publishing Group, v. 20, n. 2, 2017.

GIBSON, G. L. E. Y. Y. R.; ROBERFROID, M. B. Dietary Modulation of the Human Colonie Microbiota : Introducing the Concept of Prebiotics. The Journal of nutrition, v. 125, n. 6, p. 1401-12, 1995.

HAYLEY, S.; AUDET, M.; ANISMAN, H. Science Direct Inflammation and the microbiome : implications for depressive disorders. Current Opinion in Pharmacology, v. 29, p. 42-46, 2016.

HILL, C. et al. The international scientific association for probiotics and prebiotics consensus statement on the scope and appropriate use of the term probiotic. Nature Reviews Gastroenterology and Hepatology, v. 11, n. 8, p. 506-514, 2014.

HOMBERG, J. R.; KOLK, S. M.; SCHUBERT, D. Editorial perspective of the Research Topic "Deciphering serotonin's role in neurodevelopment". Frontiers in Cellular Neuroscience, v. 7, n. November, p. 1-2, 2013.

HOOPER, L. V. Commensal Host-Bacterial Relationships in the Gut. Science, v. 292, n. 5519, p. 1115-1118, 2001.

HOOPER, L. V.; MACPHERSON, A. J. Immune adaptations that maintain homeostasis with the intestinal microbiota. Nature Reviews Immunology, v. 10, n. 3, p. 159-169, 2010.

HUTTENHOWER, C. et al. Structure, function and diversity of the healthy human microbiome. Nature, v. 486, n. 7402, p. 207-214, 2012.

IIZUMI, T. et al. Gut Microbiome and Antibiotics. Archives of Medical Research, v. 48, n. 8, p. 727-734, 2017.

JOFFRE, O. Inflammatory signals in dendritic cell activation and the induction of adaptive immunity. Immunological Reviews, p. 234-247, 2009.

KELLER, J. et al. HPA axis in major depression : cortisol, clinical symptomatology and genetic variation predict cognition. Molecular Psychiatry, v. 2, n. May, p. 1-10, 2016.

LE BASTARD, Q. et al. Systematic review: human gut dysbiosis induced by nonantibiotic prescription medications. Alimentary Pharmacology and Therapeutics, v. 47, n. 3, p. 332-345, 2017.

LEY, R. E. et al. Obesity alters gut microbial ecology. Proceedings of the National 
Academy of Sciences, v. 102, n. 31, p. 11070-11075, 2005.

LI, W. et al. Memory and learning behavior in mice is temporally associated with dietinduced alterations in gut bacteria. Physiology and Behavior, v. 96, n. 4-5, p. 557-567, 2009.

MADSEN, K. et al. Probiotic bacteria enhance murine and human intestinal epithelial barrier function. Gastroenterology, v. 121, n. 3, p. 580-591, 2001.

MANIAR, K. et al. A story of metformin-butyrate synergism to control various pathological conditions as a consequence of gut microbiome modification: Genesis of a wonder drug? Pharmacological Research, v. 117, p. 103-128, 2017.

MATSUOKA, K.; KANAI, T. The gut microbiota and inflammatory bowel disease. Seminars in Immunopathology, p. 47-55, 2015.

MAYER, E. A. Gut feelings: the emerging biology of gut-brain communication. Nature Reviews Neuroscience, v. 12, n. 8, p. 453-466, 2011.

MEDINI, D. et al. Microbiology in the post-genomic era. Nature Reviews Microbiology, v. 6, n. 6, p. 419-430, 2008.

MESSAOUDI, M. et al. Assessment of psychotropic-like properties of a probiotic formulation (Lactobacillus helveticus R0052 and Bifidobacterium longum R0175) in rats and human subjects. British Journal of Nutrition, v. 105, n. 5, p. 755-764, 2011.

MILLER, A. H.; MALETIC, V.; RAISON, C. L. Inflammation and Its Discontents : The Role of Cytokines in the Pathophysiology of Major Depression. Biological Psychiatry, v. 65, n. 9, p. 732-741, 2008.

MOLLOY, C. A. Prevalence of chronic gastrointestinal symptoms in children with autism and. Autism, v. 7, n. 2, p. 165-171, 2003.

MULLER, C. L.; ANACKER, A. M. J.; VEENSTRA-VANDERWEELE, J. The serotonin system in autism spectrum disorder: From biomarker to animal models. Neuroscience, v. 321, n. November, p. 24-41, 2016.

NEYRINCK, A. M. et al. Wheat-derived arabinoxylan oligosaccharides with prebiotic effect increase satietogenic gut peptides and reduce metabolic endotoxemia in dietinduced obese mice. Nutrition and Diabetes, v. 2, n. JANUARY, 2012.

NOBLE, E. E.; HSU, T. M.; KANOSKI, S. E. Gut to brain dysbiosis: mechanisms linking Western Diet consumption, the microbiome, and cognitive impairment. Frontiers in Behavioral Neuroscience, v. 11, n. January, p. 9, 2017.

O'MAHONY, S. M. et al. Serotonin, tryptophan metabolism and the brain-gutmicrobiome axis. Elsevier, v. 277, p. 32-48, 2014.

PARASHAR, A.; UDAYABANU, M. Gut microbiota: Implications in Parkinson's disease. Parkinsonism \& Related Disorders, 2017. 
PHILIPPE, G. Gut Microbiome and Obesity. Annals of the American Thoracic Society, v. 14, n. November, p. 14-16, 2017.

RAMIAH, K.; REENEN, C. A. VAN; DICKS, L. M. T. Surface-bound proteins of Lactobacillus plantarum 423 that contribute to adhesion of Caco-2 cells and their role in competitive exclusion and displacement of Clostridium sporogenes and Enterococcus faecalis. Elsevier Research in Microbiology, v. 159, p. 470-475, 2008.

REA, K.; DINAN, T. G.; CRYAN, J. F. The microbiome: A key regulator of stress and neuroinflammation. Neurobiology of Stress, v. 4, p. 23-33, 2016.

RHEE, S. H.; POTHOULAKIS, C.; MAYER, E. A. Principles and clinical implications of the brain-gut-enteric microbiota axis. Nature Reviews Gastroenterology \& Hepatology, v. 6, n. 5, p. 306-314, 2009.

RIDAURA, V. K. et al. Gut microbiota from twins discordant for obesity modulate metabolism in mice. Science, v. 341, n. 6150, 2013.

RUFF, W. E.; KRIEGEL, M. A. Autoimmune host-microbiota interactions at barrier sites and beyond. Trends in Molecular Medicine, v. 21, n. 4, p. 223-244, 2015.

SAMUEL, B. S. et al. Effects of the gut microbiota on host adiposity are modulated by the short-chain fatty-acid binding $G$ protein-coupled receptor , Gpr41. Proceedings Of The National Academy Of Sciences, v. 105, n. 43, p. 16767-16772, 2008.

SANDHU, K. V et al. Feeding the Microbiota-Gut-Brain Axis: Diet, Microbiome and Neuropsychiatry. Translational Research, 2016.

SANZ, Y. et al. Understanding the role of gut microbiome in metabolic disease risk. Pediatric Research, 2014.

SAULNIER, D. M. et al. The intestinal microbiome, probiotics and prebiotics in neurogastroenterology. Gut microbes, v. 4, n. 1, p. 17-27, 2013.

SAVIGNAC, H. M. et al. Prebiotic administration normalizes lipopolysaccharide (LPS)induced anxiety and cortical 5-HT2A receptor and IL1- $\beta$ levels in male mice. Brain, Behavior, and Immunity, v. 52, p. 120-131, 2016.

SCHMIDT, T. S. B.; RAES, J.; BORK, P. Review The Human Gut Microbiome : From Association to Modulation. Cell, v. 172, n. 6, p. 1198-1215, 2018.

SEKIROV, I.; RUSSELL, S.; ANTUNES, L. Gut microbiota in health and disease. Physiological Reviews, v. 90, n. 3, p. 859-904, 2010.

SENGUPTA, R. et al. The Role of Cell Surface Architecture of Lactobacilli in HostMicrobe Interactions in the Gastrointestinal Tract. Mediators Of Inflammation, [s.1.], v. 2013, p.1-16, 2013. 
SERVIN, A. L. Antagonistic activities of lactobacilli and bifidobacteria against microbial pathogens. FEMS Microbiology Reviews, v. 28, n. 4, p. 405-440, 2004.

SHOAF, K. et al. Prebiotic galactooligosaccharides reduce adherence of enteropathogenic Escherichia coli to tissue culture cells. Infection and Immunity, v. 74, n. 12, p. 6920-6928, 2006.

SPANOGIANNOPOULOS, P.; TURNBAUGH, P. J. Broad collateral damage of drugs against the gut microbiome. Nature Reviews Gastroenterology \& Hepatology, p. 1, 2018.

THOMAS, R. H. et al. The enteric bacterial metabolite propionic acid alters brain and plasma phospholipid molecular species: further development of a rodent model of autism spectrum disorders. Journal of Neuroinflammation, v. 9, n. 1, p. 695, 2012.

TRIPATHI, A. et al. The gut-liver axis and the intersection with the microbiome. Nature Reviews Gastroenterology \& Hepatology, n. Box 1, 2018.

TURNBAUGH, P. J. et al. An obesity-associated gut microbiome with increased capacity for energy harvest. Nature, v. 444, n. 7122, p. 1027-131, 2006.

UKENA, S. N. et al. Probiotic Escherichia coli Nissle 1917 inhibits leaky gut by enhancing mucosal integrity. PLoS ONE, v. 2, n. 12, 2007.

VÁZQUEZ-BAEZA, Y. et al. Impacts of the Human Gut Microbiome on Therapeutics. Annual review of pharmacology and toxicology, n. September 2017, p. 1-18, 2017.

WANG, J. et al. Modulation of gut microbiota during probiotic-mediated attenuation of metabolic syndrome in high fat diet-fed mice. The International Society for Microbial Ecolog Journal, v. 9, n. 1, p. 1-15, 2015.

WESTFALL, S. et al. Microbiome, probiotics and neurodegenerative diseases: deciphering the gut brain axis. Cellular and Molecular Life Sciences, v. 74, n. 20, p. 37693787, 2017.

WU, H. et al. Metformin alters the gut microbiome of individuals with treatment-naive type 2 diabetes, contributing to the therapeutic effects of the drug. Nature Medicine, v. 23, n. 7, p. 850-858, 2017.

XU, M. Q. et al. Fecal microbiota transplantation broadening its application beyond intestinal disorders. World Journal of Gastroenterology, v. 21, n. 1, p. 102-111, 2015.

ZAREIE, M. et al. Probiotics prevent bacterial translocation and improve intestinal barrier function in rats following chronic psychological stress. Gut, v. 55, n. 11, p. 15531560, 2006. 